\title{
The Influence of COVID-19 on Air Quality in India: A Boon or Inutile
}

\author{
Sneha Gautam ${ }^{1}$
}

Received: 23 April 2020 / Accepted: 6 May 2020 / Published online: 11 May 2020

(c) Springer Science+Business Media, LLC, part of Springer Nature 2020

\begin{abstract}
Corona virus diseases-2019 (COVID-19), an infectious disease identified in late December, 2019, in Wuhan city of China, was declared a pandemic by the World Health Organization. Most countries including India have announced some sort of lockdown to reduce the effects of COVID-19 and discontinue the transmission of novel coronavirus. Major negative effects on the social and surrounding environment have been reported due to COVID-19, however positive effects have also been observed with respect to air quality. Secondary results have been taken from National Aeronautics and Space Administration (NASA), indicating significant reduction (50\%) in air quality of Indian region. This perspective highlights the effects of the lockdown due to COVID-19 on aerosol optical thickness specifically in India.
\end{abstract}

Keywords Air quality $\cdot$ COVID-19 $\cdot$ Environmental pollution $\cdot$ India

Novel coronavirus was reported for the first time in Wuhan district of China in the month of December, 2019 (Gautam and Hens 2020). Thereafter, the coronavirus transmitted rapidly and affected a number of people within a month (WHO 2020; Gautam and Trivedi 2020; Sharma et al. 2020). Gautam and Hens (2020) reported the information about the first affected person by SARS-CoV-2 in Kerala state of India in late January 2020. They also highlighted the travel history of the affected person, who returned from China. After the month, Kerala state was the top most state in India having a number of cases affected by Novel Coronavirus due to rapid transmission to all surrounding people with unprotected contact. At the time of writing this, a total of 488 deaths have been reported with 14792 infected persons in India due to novel COVID-19 (Aajtak.intoday.in/:18 April, 2020). The highest and lowest cases due to COVID-19 were reported in Maharashtra and Mizoram, respectively (Gautam and Hens 2020). In this regard, a 21-days nationwide "Curfew/Lockdown announced by the prime minister of India- - Narendra Modi", to reduce effects and transmission of coronavirus. As per announcement/notification of lockdown in India, all the academic institutes, industries, markets and all public places were closed until the next notification. The outcomes

Sneha Gautam

snehagautam@karunya.edu

1 Karunya Institute of Technology and Sciences, Coimbatore, Tamil Nadu 641114, India of this step taken by Government of India, were that less numbers of deaths reported in India so far as compared to other countries and air pollution levels in India, especially in New Delhi where a 50\% reduction was observed. Figure 1 shows that air pollution over northern India has recorded a 20-year-low for this time of the year (NASA 2020). Figure 1, shows AOD concentration level in India during 2016 and 2020.

Figure 1 was created using a collected data set by MODIS (Moderate Resolution Imaging Spectroradiometer) aboard NASA's Terra and Aqua satellites (i.e., Sentinel-5P and AURA) that measures size distribution and optical depth of ambient aerosol over the globe on an hourly basis. The decrease in concentration level of AOD was estimated after just a week of reduced human activities. The presented images are collected from NASA Earth Observatory showing AOD measurements over Indian region during the period of March 31 to April 5 from 2016 to 2020. Moreover, the last (sixth) anomaly image in Fig. 1, indicating the AOD average in 2020 compared to the 2016-2019 (average). It can be observed that dark brown pixels, tan pixels and light yellow areas show high, lower and little to no aerosol concentrations (Fig. 1). Aerosol is one of the important pollutants identified by national and international agencies, associated with mobility and mortality (Dutheil et al. 2020; Humbal et al. 2019). In this study, the variations of AOD which were collected from the satellite (Sentinel-5P) were used to indicate a marked difference in the levels of aerosol which are at 

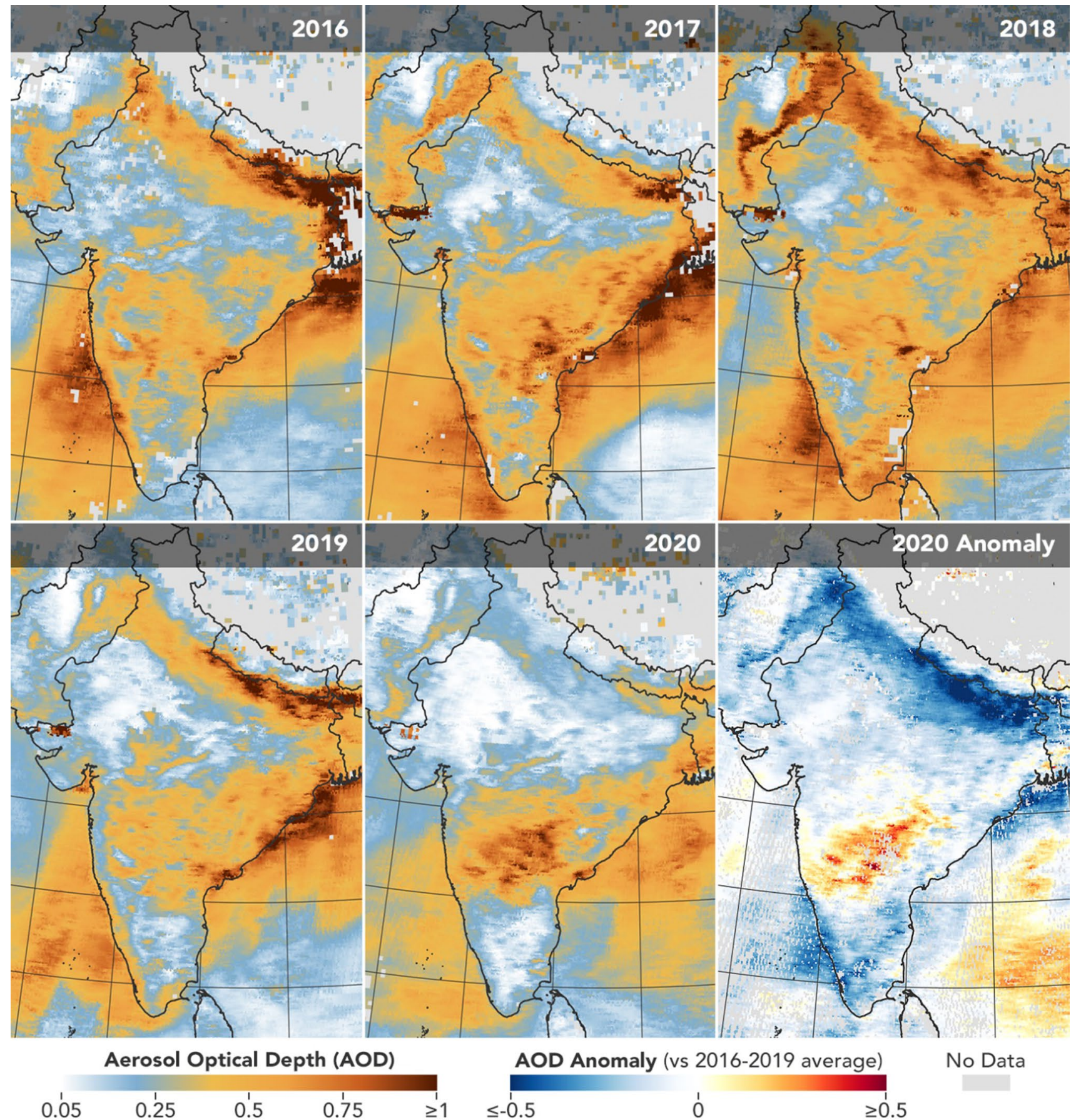
0.05
0.25
0.5
0.75

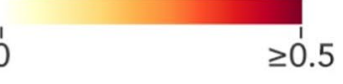

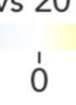

Fig. 1 Sequence of aerosol optical thickness concentration (month-Terra/Modis) in India from the period of March 31 to April 5 in 2016, 2017, 2018, 2019 and 2020 (NASA 2020)

its lowest in 20 years due to COVID-19 lockdowns (NASA 2020). The outcomes indicate that the novel coronavirus is considered as a blessing in disguise. The current status of air quality may be temporary but there is a very good opportunity for us (scientists/researchers/students/individuals) to learn/understand from applied lockdown activities on how to minimize the concentration level of air pollutants on a long term basis. Donkelaar et al. (2010) suggested that air pollution contributes to the large global burden of respiratory diseases (i.e., pneumonia, chronic obstructive pulmonary disease, asthma and possibly tuberculosis). According to WHO (2018), 4.2 million premature deaths were reported in the year of 2016 due to ambient air pollution. So, as per the air quality index is concerned, the current enhancement 
in air quality of India, would avert significant premature deaths due to air pollution on a monthly/annually basis. Recent results over the last few years have reported results from global to molecular scales an increased understanding of bio aerosol and its health effects (Humbal et al. 2020; Humbal et al. 2018). However, further research is required to understand the open questions based on interdisciplinary and complex nature of aerosol with respect the relationship with human health (Kagaya et al. 2020; Muhammad et al. 2020). The following points are based on epidemiological, global modeling studies, aerosol, andhealth related health issues and are prioritized to improve assessment of mortality due to air pollution: (1) health effects due to specific biotic components and their source could be clarified by epidemiological studies. The different chemical composition/characterization and toxicity of biotic components needs to be investigated; (2) epidemiological cohort studies are highly needed especially in African and Asian countries where aerosol /bio aerosol and its exposure based studies have not been effectively introduced; (3) No-Observed-Adverse-Effect (NOVEL) or lowest-observed-Adverse-Effect (LOAEL)-cost devices are required to understand the integration of personal exposure in term of assessments; and (4) the relationship of lung surfactants and aerosol components need to be studied. Similar opinions could be applied to other COVID-19 affected countries, as of April 18, 2020, there are 2284018 infected persons and 156140 reported deaths from COVID-19 in and around the world.

This perspective provides evidence of significant changes in air quality of the Indian region during the government lockdown order to reduce the effects of COVID-19. According to the results and discussion, it can be considered that the massive reduction of aerosol concentration during quarantine, novel coronavirus might paradoxically have reduced the percentage of deaths during the period, by significantly reducing the percentage of fatalities due to degradation of air quality.

\section{References}

Donkelaar AV, Martin RV, Brauer M et al (2010) Global estimates of ambient fine particulate matter concentrations from satellite-based aerosol optical depth: development and application. Environ Health Perspect 118(6):847-855

Dutheil F, Baker SJ, Navel V (2020) COVID-19 as a factor influencing air pollution? Environ Pollut. https://doi.org/10.1016/j.envpo 1.2020 .114466

Gautam S, Trivedi UK (2020) Global implications of bio-aerosol in pandemic. Environ Dev Sustain 22:3861-3865

Gautam S, Hens L (2020) SARS-CoV-2 pandemic in India: what might we expect? Environ Dev Sustain 22:3867-3869

Humbal C, Gautam S, Trivedi UK (2018) A review on recent progress in observations, and health effects of bioaerosols. Environ Int 118:189-193

Humbal C, Gautam S et al (2019) Evaluating the colonization and distribution of fungal and bacterial bioaerosol in Rajkot, western India using multi-proxy approach. Air Qual Atmos Health 12(6):693-704

Humbal C, Gautam S, Joshi SK, Rajput MS (2020) Spatial variation of airborne allergenic fungal spores in the ambient PM2.5a study in Rajkot City, Western Part of India. In: Gupta et al (ed) Measurement, analysis and remediation of environmental pollutants, Springer, Singapore, pp. 199-209. https://doi. org/10.1007/978-981-15-0540-9

Kagaya MK et al (2020) Estimating the asymptomatic proportion of coronavirus disease 2019 (COVID-19) cases on board the Diamond Princess cruise ship, Yokohama, Japan, 2020. Euro Surveill 25:2000180

Muhammad S, Long X, Salman M (2020) Covid-19 pandemic and environmental pollution: a blessing in disguise? Sci Total Environ $728: 138820$

NASA (2020) NASA, 2020. https://earthobservatory.nasa.gov/image s. Accessed 1 May 2020

Sharma S, Zhang M, Anshika, Gao J, Zhang H, Kota SH (2020) Effect of restricted emissions during COVID-19 on air quality in India. Sci Total Environ. https://doi.org/10.1016/j.scitotenv.2020.138878

World Health Organization (2018) Ambient (outdoor) air pollution. Key facts. World Health Organization. https://www.who.int/news$\mathrm{room} /$ fact-sheets/detail/ambient-(outdoor)-air-quality-and-health. Accessed 23 Apr 2020

World Health Organization (2020) Coronavirus disease (COVID-2019) situation reports. World Health Organization, Geneva. https:// www.who.int/emergencies/diseases/novel-coronavirus-2019/situa tion-reports/.opensinnewtab. Accessed 23 Mar 2020

Publisher's Note Springer Nature remains neutral with regard to jurisdictional claims in published maps and institutional affiliations. 